held under such pleasant circumstances, I shall notice it, with a very short allusion to the antecedent.

That some surgeons would operate in such a case as the above, I am well aware; but, most assuredly, a very large majority would not; and I beg to say, as a last remark, that I am not attempting to lay down any new doctrine, but merely desire to draw more general atten. tion to this one particular, that very undoubted, considerable, and peculiar advantages, may be conferred by an operation on the victim of cancer, even after the ul. cerative stage is established.

69 , Brook Street, Hanover Square, W.

\section{ON THE ACTION OF THE BRONCHIAL MUSCLES.}

By C. Radclyffe Hall, M.D., F.R.C.P., Physician to the Hospital for Consumption, Torquay; etc.

THE perusal in the Medical Times and Gazette of Dr. Hyde Salter's interesting criticism on Dr. Kidd's view of the pathology of asthma, tempts me to say a word in defence of that hypothesis concerning the action of the bronchial muscles, which they both alike reject.

Dr. Kidd considers that the bronchial muscles are inspiratory, and that they cause contraction of the tubes during ordinary inspiration.

Dr. Hyde Salter considers them not "muscles of respiration at all, either of expiration or inspiration."

Haller, Reisseissen, Elliotson, and others, suppose that the bronchial muscles act as auxiliary agents in ordinary expiration. Dr. C. J. B. Williams appears to be of the same opinion. In the Transactions of the British Medical Association for 1850 (p. 363), I published a paper, in which $I$ endeavoured by experiments to substantiate this view. And, unless I remember inaccurately his remarks in conversation, Dr. Brown-Séquard has come to the same conclusion.

There are then three conjectures at present entertained respecting the function of the bronchial muscles.

1. That they contract in ordinary inspiration.

2 . That they contract in ordinary expiration.

3. That they contract only occasionally to expel irritating matters, or in answer to morbid sensations, either in the quick manner of cough, or in the persistent manner of spasm.

This last proposition, apart from its exclusiveness, few will be disposed to deny. Dr. Hyde Salter has excellently well argued that spasm of the bronchial muscles is the sine qua non of true asthma; is indeed the only explanation that will fully work the problem of the disease.

When on each contraction of the heart a wave of blood distends a small artery, the elastic and muscular coats of the blood-vessel yield, and the vessel expands. This answers to inspiration; excepting that, in the case of the circulation, the motor force is from the centre; in that of the respiration, from the circumference. As regards the artery and the bronchial tube, this difference may for the moment be left out of consideration. Immediately after its distension, the artery slightly contracts, and by so doing quickens the onward flow of its contents. This answers to expiration. Galvanise the blood-vessels in a suitable manner, and the small arteries contract. Or, without that, expose the skin to cold, or the mouth to ice, and the same will happen.* This tonic contraction of the blood-vessels answers to asthma.

Hence, the view I am contending for assumes that the bronchial muscles contract slightly for every expira-

* A possibility to be remembered in directing ice to be sucked continuously when the patient is of feeble vital power. Twice in the last year I have seen viceration of the tongue, or of the inside of the cheeks or lips, attributable to this. The ice constringed the bloodvessels so considerably and so long as to induce molecular deathulceration. tion; contract more vigorously and suddenly for every cough; and contract in the persistent spasmodic man. ner in every case of asthma.

The larynx and glottis expand for inspiration, and contract for expiration. The glottis can contract vigorously and suddenly, as in cough; or in the shape of spasm of more or less duration, in laryngismus, in hooping-cough, and in croup. Laryngismus may be considered as an infantile laryngeal asthma. I assume that the remainder of the respiratory tubing in all these respects follows suit.

The smallest bronchial tubes are the most muscular. The larger tubes have the most of those elastic-spring openers, the bronchial cartilages. Hence, the bronchial muscles will mainly operate in the tubes which lie nearest to the finer and more delicate parts of the lung, the vestibular passages and air-cells.

We will assume that the ordinary excitor to action of the bronchial muscles is the disterision of the tube by inspired air. This will take place just after the end of inspiration, when the newly arrived air has undergone expansion by warmth; that is, provided the in-rush be gentle and gradual, as in quiet healthy breathing. But in proportion as the in-rush is sudden, abrupt, and forcible, as when a person is out of breath from running, will the bronchial muscles act vigorously, not to promote inspiration, but to oppose it, and so prevent it from inducing more than a certain safe amount of distension of tubes.

In expiration, the compressed air-cells expel a portion of their air with a given force. The expulsion will be quickened by lessening the bore of the exit channel, provided the expelling force remain adequate. And this quickening of exit will take place most precisely where it is most necessary to get rid of foul air speedily ; viz., in the smallest bronchial tubes which are nearest to the air-cells; less and less as the tubes become larger, and intermixture of foul with fresh air readier; for it must be remembered that, at the moment when expiration commences in the periphery of the lungs, the larger tubes are still full of unused air.

The objection usually urged against the supposition that the bronchial muscles assist in the act of expiration is, that the contraction of a bronchial tube would oppose, and not facilitate the passage of air out, just as it does the passage of air in. This would be so, provided the bore of the tube were lessened out of proportion to the motor force, and provided it were kept persistently in the contracted condition. Within suitable limits, by lessening bore, rate is quickened and volume lessened. And so long as the proper balance is preserved between the quickening effect of lessened calibre of bronchial tube and the amount of propelling power from behind in expiration, we may assume that as much may be gained by increase of speed as is lost by diminution of channel. If the objection were valid, it would be equally strong against the case of the glottis, or that of the artery. Contraction of the glottis must impede both the ingoing and the outgoing of the air, and does so in various morbid conditions. Yet, in the normal state of things, the glottis does expand for inspiration and contract for expiration.

The same person using the spirometer finds that he cannot do full justice to his vital capacity, if he make his trial expiration too quickly, or too slowly. He is stopped by positive inability to do more of the act of expiration, and not by the sensation of apnœa. When too quick, he finishes before he has got out all the expiratory air from the lungs, which he could by a quieter attempt expel. When too slow, he tires the expiratory machinery before he has emptied the lungs of all but the necessary residual air. I suspect that the bronchial muscles are a good deal concerned in occasioning the inadequate performance of these spirometric expirations. The latter portion of the expiration consists in 
an erident squeezing out of the air from the bronchial tubes. If expiration have been commenced gently and carried on smoothly and not too slowly, the air is first cxpelled evenly from the air-cells, then pushed on by the contracting tabes unti] their muscles are tired. If the tubes be contracted too quickly lefore the remove. abb air is all ont of the air-cells, the bronchial muscles hare done their work too $800 \mathrm{n}$. If the expiratory effort be made too slowly, the bronchial muscles also become tired before they have completed the full expulsion of air. This bypothesis, at least, seems to fit the facts so familiar to every one who makes habitual usc of the spirometer in his practice.

I assume the following propositions.

1. The bronchial musoles are expiratory muscles. They coatract rhythmically in quiet normal expiration, and by 80 doing quicken expulsion of foul air from the air-cells, and socommodate the size of the tubes to the lessening bulk of the lung. In forcible expiration, the thorax govarns the lungs during the major portion of the act; but at the terminal point of squeezing out the last portions of expirable air, the contraction of the bronchial muscles is tho chief agent, and the lungs govern the thorax in accommodating its size to theirs.

2. The bronebial muscles are never inspiratory musabs. They oppose undue force of inspiration when it comes to bear upon thelessertubes, and so become regulators of the amount of air admitted.

3. The bronchial muscles under abnormal circum. tances can act during either inspiration or expiration. Ther ect with irregular rehemence in cough; with clonic spasm in hooping cough; with tonic spasm in axthme.

There is another point of physiological interest, in which in all probability the bronchial muscles play the principal part. It is a very common fallacy, that the oxygeantion of the blood is governed almost entirely br the imount of oxygen present in the surrounding atmosphere. In reality it is governed exclusirely by the quantity of arygen which gains admission into the blood through the walls of the air-cells; and this depends upon several other things besides the amount of oxygen in the atmosphere. That of course is one element; but the state of the lungs, and the need of oxygen in the system, are far more influential elements. There is less oxygen in a cubic foot of air on a mountain-top than in a low bottom; and yet, in consequence of the energising effect of mountain-air, healthy person will generally use up more. There is less oxygen on a soft day with the barometer low and the wind in the west, than on a sharp dry day with the harometer high and the wind in the east. Iet a person with sensitive lungs will use up more on the warm day, because he will take in more. He will fll his chest better, and can tell by his own sensations that he does so. He feels that the air goes deeper; that, to use a familiar phrase, "it gets into his lungs." On the east-wind.day, be feels a sense of constriction; the air does not get into every nook and crevice, because, metaphorically speaking, his lungs do not like the air and refuse to have it. Hence, although there is more oxygen for healthy lungs in a cold bracing place, and in winter, there is really more for diseased and sensitive langs in a mild climate, and in summer; simply because in the one case the lungs cannot use it to the full ex. tent, although it is there for them; and in the other, they can use it amply, and it is there to an adequate if not quite to the same extent.

Most irritating gases irritate the glottis, and so are 8hut out on the threshold; but when this is not the case they induce a sense of pulmonic constriction, which in this case, as in that of the east wind, may be largely due to reflex action of the bronchial muscles-the natural protectors of the air-cells.

\section{Cransactions of $3 x a n c b e s$.}

\section{READING BRANCH. \\ RETROSPECTIVE $\triangle D D R E S S$ OF THE READINA PATHOLOGICAL SOCIBTY.}

By O. C. Matrice, Esq., Honse-Surgeon to the Rojal Berkshire Hospital.

[Read July 2tck.]

[Continued from page 609.]

Onstetrical Cases.

Uterine Hydatids. Dr. Woodhouse presented an organised substance resembling a placenta, thickly s:udded with hydatids, passed hy a woman aged 15 , the mother of six children. For about six months she had a bloody discharge, which she always looked on as the catamenial flow at the change of life, and of which she took no particular notice. Dr. Woodhouse, on seeing her, proscribed astringent mixtures, and enjoined rest, to which, however, she did not adhere; nor would she permit an examination per vaginam, or the cause of hæmorrhage might have been discovered.

Hydrocephalus in Utero. Mr. Harrinson communi. cated the case of a woman aged 28 , who was four days in her second labour. On the first day, it was stated, that a large quantity of liquor amnii escaped; and a large semisolid substance was felt abore tho brim of the pelvis, snd protruded into the cavity at every feeble pain. During the following three days, labour adranced but little; the pains continuing weak and nonexpulsire. She became greatly exhausted between the intervals of pain, the swelling being less distended. By diving deeply with the finger, it came into contact with a sharp and irregular edge of bone, resting on the brim of the pelvis, which was determined to be one of the cranial bones, and led to the conclusion that hydrocephalus was the complication, and perforation the only means of affording relief. The presenting part was perforated during the access of a pain; about two pints of fluid were collected, and about the same quantity saturated the bed. Continuous contraction of the uterus now commenced; the collapsed head, and quickly the whole body, were expelled. The placenta came readily away, and the case did well.

India-rubber Pessary. Mr. G. May presented an India-rubber pessary capable of being dilated to any extent, which be stated he bad found most useful, in induciug premature labour, in hæmorrhage from placenta prævis, and in post partum hæmorrhage.

Anencephalous Infant. MIr. Harrinson read the case. Irs. S., a delicate woman, aged 22, was delivered before her time of her first child. When first seen, the presenting part was pressing on the perinæum, and the pains were vigorous. The presenting part could not be recognised as belonging to a child in its normal state but the head was quickly expeiled, the face looking towards the pubes. The child was dead, and the remaining stages presented nothing remarkable.

Hydrorrhoea, or Watery Discharge in Pregnant Homen. Mr. Harrinson presented the case, and at the same time referred to other cases published by him in the Britise MEDICAL Jorrsal, in which he sought to establish the fact that such discharges originated in a limited separation of the placenta, it being attached to the immediate neighbourhood of the os uteri. He stated that this case further illustrated the correctness of such pathology.

A weak, delicate woman, aged 33 , when six weeks advauced in her fourth pregnancy, had a coloured dis. charge, which continued more or less for two months. After an interval of some weeks, the watery discharge began and recurred occasionally in gusbes of about half a pint in quantity at intervals of about a month. 